\title{
Late ophthalmology findings in a X-linked juvenile retinoschisis patient
}

\author{
Achados oftalmológicos tardios em um paciente portador \\ de retinosquise juvenil ligada ao cromossomo $X$.
}

Paulo Rodolfo Tagliari Barbisan' https://orcid.org/0000-0001-7680-5428

Paulo Antonio Barbisan' https://orcid.org/0000-0001-8905-8820

\begin{abstract}
$X$-linked juvenile retinoschisis (XLRS) is a vitreoretinal degeneration caused by mutations in the RS1 gene, generally characterized by bilateral maculopathy and peripheral retinoschisis leading to progressive visual loss during the first 2 decades of life and complications like retinal detachment and vitreous hemorrhage. Herein, we present late ophthalmology findings in a XLRS patient.
\end{abstract}

Keywords: Genetic diseases, X-linked; Retinoschisis/diagnosis; Tomography, optical coherence / methods; Child

\section{RESUMO}

A retinosquise juvenil ligada ao cromossomo X (XLRS) é uma degeneração vitreorretiniana causada por mutaçoes no gene RS1, geralmente caracterizada por maculopatia bilateral e retinosquise periférica, levando à perda visual progressiva durante as primeiras 2 décadas de vida e complicações como descolamento de retina e hemorragia vítrea. Apresentamos aqui achados oftalmológicos tardios em um paciente com XLRS.

Descritores: Doenças genéticas ligadas ao cromossomo X; Retinosquise/diagnóstico;Tomografia de coerência óptica/métodos; Criança

'Clínica de Olhos Santa Luzia, Ribeirão Preto, SP, Brazil.

The authors declare no conflict of interest

Received for publication 17/2/2019 - Accepted for publication 6/7/2020. 


\section{INTRODUCTION}

$\mathbf{X}$ -linked juvenile retinoschisis (XLRS) is an inherited, recessive, vitreoretinal degeneration caused by mutations in the RS1 gene, encoding the retinoschisin protein which leads to schisis (splitting) of the neural retina. ${ }^{(1,2)}$ Defects or the absence of this protein may lead to intraretinal microcystic development, while a coalescence of these microcysts results in retinoschisis, most commonly progressing from the outer plexiform layer or the inner nuclear layer to the inner retinal strata, ${ }^{(3)}$ different from retinal detachment which is a split between the neural retina and the retinal pigment epithelium. The condition accounts for almost all congenital retinoschisis with occasional reports of autosomal dominant pattern. ${ }^{(3)}$ XLRS is more common in young males, having a bilateral appearance in $40 \%$ of the patients and its prevalence is estimated to be up to 1 in 20.000 , although is likely to be underdiagnosed. ${ }^{(2)}$

There is a great variation in disease severity even among individuals who have the same causative RS1 mutation, but it is generally characterized by bilateral maculopathy and peripheral retinoschisis in about $50 \%$ of the patients, most often localized in the inferotemporal quadrant. XLRS patients usually present at school age with poor vision and reading difficulties, with best-corrected visual acuity (BCVA) from 20/20 to 20/600, ${ }^{(4)}$ leading to progressive visual loss during the first 2 decades of life, although stabilization of visual acuity until the fifth or sixth decade has also been observed. ${ }^{(2,5)}$

Clinically, patients present a characteristic macular involvement called foveoschisis, seen as a cartwheel pattern of folds radiating out from the fovea, present in $98-100 \%$ of cases, although over time this may become less distinct. ${ }^{(2,5)}$ Additional peripheral changes may include pigmentation, which can resemble retinitis pigmentosa, sublinear retinal fibrosis and vascular attenuation or sheathing. ${ }^{(2.5)}$ Optical coherence tomography (OCT) shows widespread cystic spaces and disorganization of the retinal layers in XLRS patients (similar to cystoid macular edema), however they do not present late leakage in fluorescein angiography, since there is no vascular involvement in the origin of the cysts. ${ }^{(6,7)}$ Others diagnostic exams like electroretinogram (ERG), blood test and genetic testing are usually necessary to exclude differential diagnosis like congenital stationary night blindness (CSNB), Alport's syndrome, Goldmann-Favre syndrome, Eales disease and Wagner syndrome. . $1,2,3,5)^{2}$

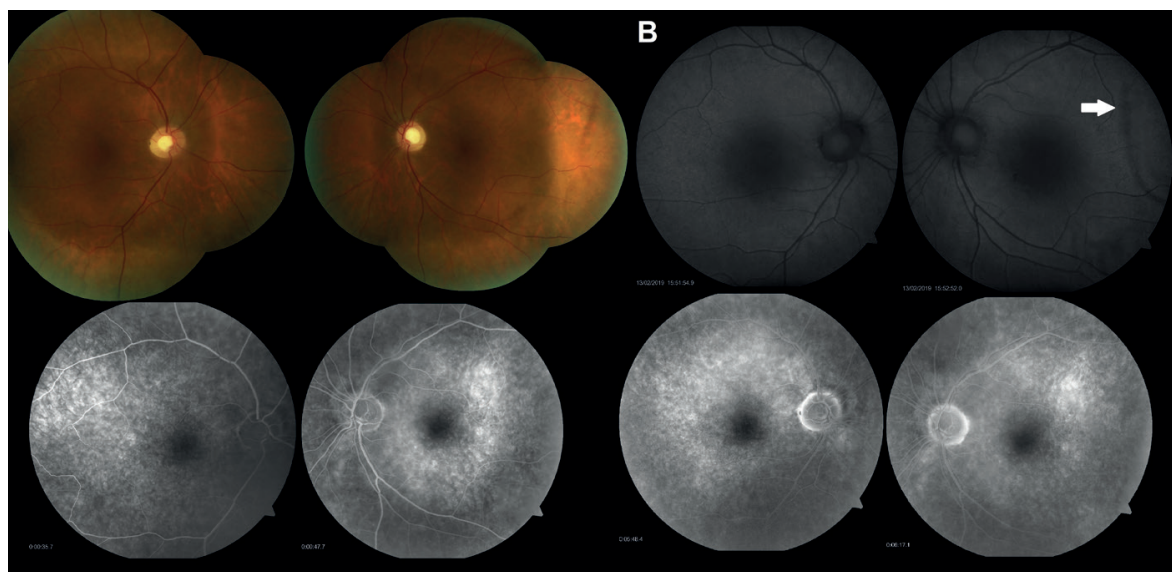

Figure 1: A: Retinography (Fundus Imaging) showing asymmetrical cupping of the optic disc, loss of regular macular pigmentation and low grade vascular attenuation. B:Autoflourescence Imaging showing normal findings and a hipoautoflourescence line in theleft eye (arrow). C: Flourescein Angiography showing an early and late hiperflourescence at the peri-macular area in both eyes.
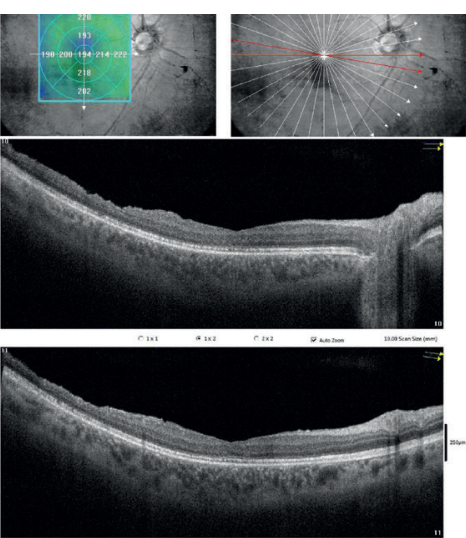
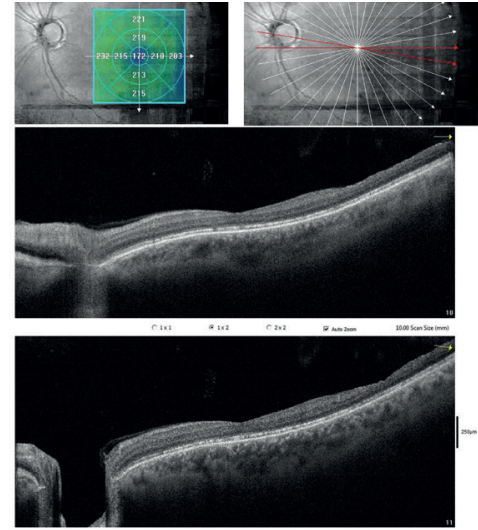

Figure 2: Optical coherence tomography (OCT) showing a general thinning of macular region with a greater thinning in the temporal region, no foveoschisis or intraretinal cysts and areas of disruption of the ellipsoid zone scattered across the macula in both eyes. 

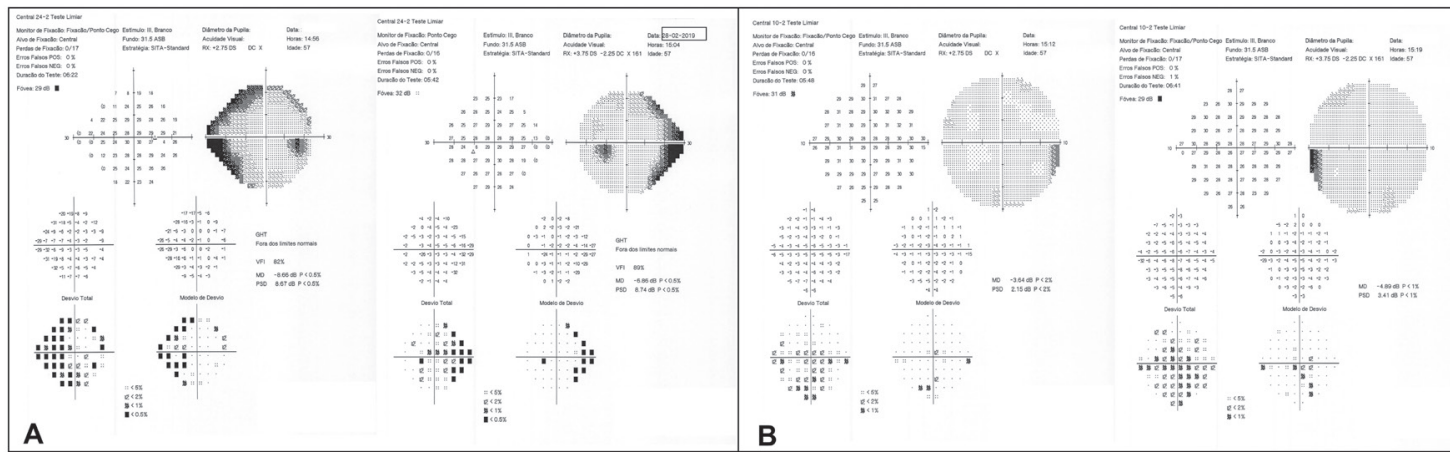

Figure 3: Visual Field (Humphrey campimetry) in both eyes showing peripheral nasal defects on 24-2 protocol (A) and general decrease of sensitivity on 10-2 protocol (B).

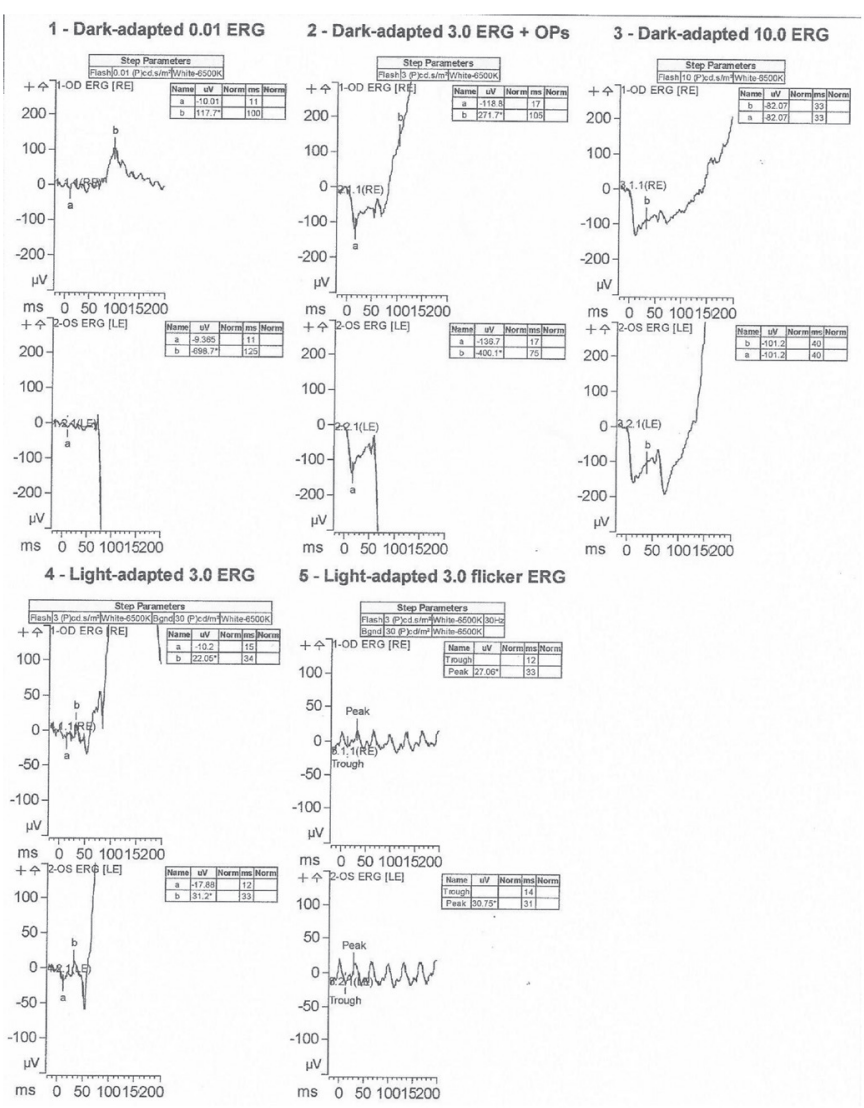

Figure 4: Full-field ERG in both eyes showing reduction of b-wave amplitude in dark-adapted ERG and discrete reduction of general amplitudes in light-adapted ERG.

Late stages of XLRS is under active investigation where some suggest no progression, while others found that after the age of 40 the macular alterations may change from the characteristic spoke-wheel pattern to unspecific, mild, retinal pigment abnormalities. ${ }^{(8)}$ Long-term monitoring is very important as during the course of the disease, secondary complications such as retinal detachment (most rhematogenous in origin from peripheral retinal breaks) and vitreous hemorrhage can occur, leading to poor visual outcome. Herein, we present late ophthalmology findings in a $\mathrm{x}$-linked juvenile retinoschisis patient.

\section{Case report}

A 57-year-old male present with low BCVA since his early childhood, episodes of hematuria and decrease night vision. He did not complain of ocular pain, redness, or any associated symptoms and had no history of dysmorphopsia, dyschromatopsia, ocular surgery/trauma, hearing problems or systemic diseases. He reported a younger brother with the same ophthalmology symptoms, but no previous diagnosis as well.

On ophthalmological examination, he had an BCVA of 20/40 (Snellen chart) in both eyes, normal intra-ocular pression (Goldmann tonometry; $13.2 \mathrm{mmHg}$ in the right eye and 12.5 $\mathrm{mmHg}$ in the left eye) and in the slit-lamp anterior biomicroscopy examination a small posterior subcapsular cataract in the visual axis in both eyes. Binocular indirect ophthalmoscopy revealed a total retina attachment, an asymmetrical cupping of the optic disc, loss of regular macular pigmentation, peripheral pigmentary abnormalities and low grade vascular attenuation (Figure 1A). Fundus autofluorescence imaging showed a hipoautoflourescence line (temporal from the macula) in the left eye (Figure 1B) and an early and late hiperflourescence at the peri-macular area in both eyes with no leakage on fluorescein angiography (Figure 1C). OCT (Avanti ${ }^{\circledR}$, Optovue) demonstrated a general thinning of macular region (central macular thickness of $194 \mu \mathrm{m}$ in the right eye and $172 \mu \mathrm{m}$ in the left eye) with a greater thinning in the temporal region, no foveoschisis or intraretinal cysts and areas of disruption of the ellipsoid zone scattered across the macula in both eyes (Figure 2). Visual Field (Humphrey ${ }^{\circledR}$ campimetry, Zeiss) in both eyes showed peripheral nasal defects on 24-2 protocol and general decrease of sensitivity on 10-2 protocol (Figure 3 ).

After these results, there were 3 possible diagnosis suggested: Alport's Syndrome, XLRS and CSNB. We performed a full-field ERG that demonstrated reduction of b-wave amplitude in dark-adapted ERG and discrete reduction of general amplitudes in light-adapted ERG (Figure 4) which can occur only in XLRS and CSNB but not in Alport's Syndrome and therefore, the last one was discarded.

Finally, we requested a genetic testing to define the diagnosis, showing the presence of the RS1 gene mutation on the chrX:18.660.161 position and thus defining the diagnosis of XLRS.

\section{Discussion}

This case report showed interesting late findings in a patient with XLRS. The typical foveoschisis and peripheral retinoschisis were not presented in this patient and instead, OCT showed 
thinning, outer retina alterations and no intraretinal cysts. The coalescence of cysts with time has already been reported ${ }^{(1,6)}$ but in this case, where there was no previous diagnosis of XLRS, others hypothesis emerged.

Alport's Syndrome was suggested based on decrease BCVA, history of hematuria and the characteristic retinal temporal thinning on $\mathrm{OCT}^{(9)}$ but the patient's abnormal ERG and the absence of others typical signs that could be present in the syndrome like hearing loss, lens and corneal abnormalities and retinal flecks, excluded this hypothesis.

Decrease night vision, reduction of b-wave amplitude in dark-adapted ERG and apparent X-linked inheritance (report of patient's brother with ophthalmology symptoms) are some characteristics of CSNB. Although this patient had these changes, he also possesed decrease BCVA and fundus abnormalities, which is not typical of CSNB.

The importance of this case report is not only to confirm previous reports of absence of foveoschisis in XLRS's late stages but to show the presence of other signs like outer retinal changes and temporal thinning on OCT, absence of peripheral retinoschisis (demarcation line was still present in this patient) and peripheral changes on visual field campimetry.

\section{ReFERENCES}

1. Sikkink SK, Biswas S, Parry NR, Stanga PE, Trump D. X-linked retinoschisis: an update. J Med Genet. 2007;44(4):225-32.

2. Molday RS, Kellner U, Weber BH. X-linked juvenile retinoschisis: clinical diagnosis, genetic analysis, and molecular mechanisms. Prog Retin Eye Res. 2012;31(3):195-212.
3. Yassur Y, Nissenkorn I, Ben-Sira I, Kaffe S, Goodman RM. Autosomal dominant inheritance of retinoschisis. Am J Ophthalmol. 1982;94(3):338-43.

4. Forsius H, Krause U, Helve J, Vuopala V, Mustonen E, Vainio-Mattila B, et al. Visual acuity in 183 cases of X-chromosomal retinoschisis. Can J Ophthalmol. 1973;8(3):385-93

5. George ND, Yates JR, Moore AT. Clinical features in affected males with X-linked retinoschisis. Arch Ophthalmol. 1996;114(3):274-80.

6. Saxena S, Manisha, Meyer CH. Three-dimensional spectral domain optical coherence tomography in $\mathrm{X}$ linked foveal retinoschisis. BMJ Case Rep. 2013;2013:bcr2012007661.

7. Ozdemir H, Karacorlu S, Karacorlu M. Optical coherence tomography findings in familial foveal retinoschisis. Am J Ophthalmol. 2004;137(1):179-81.

8. Urrets-Zavalía JA, Venturino JP, Mercado J, Urrets-Zavalía EA. Macular and extramacular optical coherence tomography findings in X-linked retinoschisis. Ophthalmic Surg Lasers Imaging. 2007;38(5):417-22.

9. Savige J, Sheth S, Leys A, Nicholson A, Mack HG, Colville D. Ocular features in Alport syndrome: pathogenesis and clinical significance. Clin J Am Soc Nephrol. 2015;10(4):703-9.

\section{Corresponding author}

Paulo Rodolfo Tagliari Barbisan

Rua Floriano Peixoto, 1853 - Alto da Boa Vista, Ribeirão Preto SP, 14025-220, Brazil

Tel : +5516991877107; +16178527449

Fax : +551639111929

E-mail : paulortbarbisan@gmail.com 